\title{
Micro-geological causes and macro-geological controlling factors of low-resistivity oil layers in the Puao Oilfield
}

\author{
Tan Fengqi ${ }^{1,2}$, Li Hongqi ${ }^{1,2 *}$, Liu Hongtao ${ }^{3}$, Jiang Fucong ${ }^{3}$ and Yu Hongyan ${ }^{1,2}$ \\ ${ }^{1}$ School of Resource and Information Technology, China University of Petroleum, Beijing 102249, China \\ ${ }^{2}$ State Key Laboratory of Petroleum Resource and Prospecting, China University of Petroleum, Beijing 102249, China \\ The No.7 Oil Production Factory, Daqing Oilfield Company, PetroChina, Heilongjiang 163515, China
}

\begin{abstract}
Low-resistivity oil layers are often missed in logging interpretation because of their resistivity close to or below the resistivity of nearby water layers. Typical low-resistivity oil layers have been found in the past few years in the Putaohua reservoir of the Puao Oilfield in the south of the Daqing placanticline by detailed exploration. Based on a study of micro-geological causes of low-resistivity oil layers, the macro-geological controlling factors were analyzed through comprehensive research of regional depositional background, geological structure, and oil-water relations combined with core, water testing, well logging, and scanning electron microscopy data. The results showed that the formation and distribution of Putaohua low-resistivity oil layers in the Puao Oilfield were controlled by depositional environment, sedimentary facies, diagenesis, motive power of hydrocarbon accumulation, and acidity and alkalinity of reservoir liquid. The low-resistivity oil layers caused by high bound-water saturation were controlled by deposition and diagenesis, those caused by high free-water saturation were controlled by structural amplitude and motive power of hydrocarbon accumulation. Those caused by formation water with high salinity were controlled by the ancient saline water depositional environment and faulted structure and those caused by additional conductivity of shale were controlled by paleoclimate and acidity and alkalinity of reservoir liquid. Consideration of both micro-geological causes and macro-geological controlling factors is important in identifying low-resistivity oil layers.
\end{abstract}

Key words: Daqing placanticline, Puao Oilfield, Putaohua oil layer, low-resistivity oil layers, microgeological causes, macro-geological controlling factors

\section{Introduction}

In low-resistivity oil layers, the ratio of the resistivity of the oil layer to that of a formation water layer is less than 2 in the same oil-water system, that is to say, the resistivity index of the oil layer is less than 2 (Ouyang et al, 2005; Zhang et al, 2008). Low-resistivity oil layers are often missed in petroleum exploration and development because of their complicated genesis, the limitation of vertical resolution of well logging instruments, and imperfect interpretation methods. At present, low-resistivity oil layers have attracted attention as one of the most promising targets for increasing reserves as well as secondary development in old oilfields (Mu et al, 2004). In China and other countries, the study on low-resistivity oil layers has acquired a great deal of achievements; for instance, people have formed a systemic understanding of micro-geological causes of low-resistivity oil layers (Zeng, 1991; Ouyang, 2002; Sun et al, 1998; Palar and Sutiyono, 1997; Worthington, 1997). However, much remains to be

*Corresponding author. email: hq.li@cup.edu.cn

Received December 15, 2008 done in the study of macro-geological controlling factors of low-resistivity oil layers and research into the matching relationship between micro-geological causes and macrogeological controlling factors has not been systematic. In this paper, various macro-geological controlling factors of the micro-geological causes of the Putaohua low-resistivity oil layers in the Punan and Aonan Oilfields, south of the Daqing placanticline, China were analyzed on the basis of core, well logging, geological and reservoir data. The results showed that a combination of micro-geological causes and macro-geological controlling factors was more important for understanding the genesis of low-resistivity oil layers. This can provide a geological basis for identifying low-resistivity oil layers effectively and adjusting development programs, and can also play an important role in exploring for zones of remaining oil.

\section{Geological background of low-resistivity oil layers in Puao Oilfield}

The Puao Oilfield is located in the southern extension zone of the Putaohua structural belt, which is a third-grade 
structural belt in the south of the secondary structural belt of the Daqing placanticline in the Central Depression of the Songliao Basin, including two development blocks of Punan Oilfield and Aonan Oilfield (Fig. 1). Many faults develop in the region and divide the structure into twelve separate fault blocks in which there are eleven oil blocks. Faults can seal oil, gas, and water, forming lithology-block reservoirs. This region belongs to the southern extension zone of the large-scale river-delta depositional system of the Daqing placanticline and is controlled by sedimentation of northern provenance. From north to south, the sedimentary facies change from delta-front facies to delta-plain facies. Shoreshallow lake facies deposits are widely distributed in southern part, and mud flat of shore-shallow lake facies appears in the southernmost part. The low-energy depositional environment supported the development of low-resistivity oil layers.

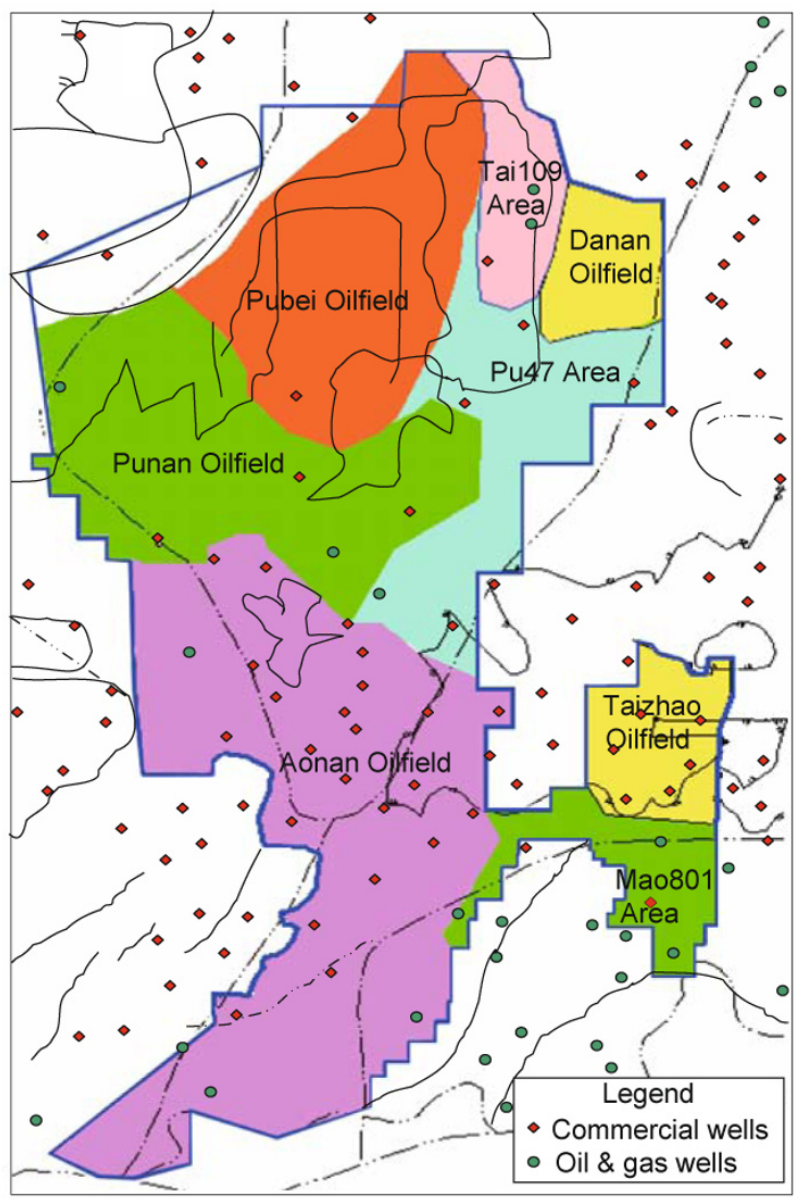

Fig. 1 Structural location of the Puao Oilfield

The main target formation of the Puao Oilfield is the Putaohua oil layer of the first section of the lower Cretaceous Yaojia Formation, which is thick in the northwest and thin in the southeast. The reservoir lithology is a set of gray siltstones and gray-green mudstones along with transition lithology. The Sapu interbed of gray-black mudstone is the top boundary marker bed of the Putaohua oil layer and is also a favorable reservoir-cap rock. The top of the Qingshankou Formation is a set of gray mudstones with steady distribution underlying the Putaohua oil layer. In recent years, typical low-resistivity oil layers have been found in the study area through detailed exploration and evaluation. The percentage of low-resistivity oil layers accounting for the total number of oil layers reaches about $30 \%$, so low-resistivity oil layers have become the focus of next-stage development in the Puao Oilfield.

\section{Macro-geological controlling factors of micro-geological causes of low-resistivity oil layers}

Micro-geological causes of low-resistivity oil layers in Puao Oilfield can be classified into two types: internal factors and external factors. The internal factors mainly include high bound-water saturation, high free-water saturation, argilliferous sandstone in a low-energy depositional environment, formation water with high salinity, and the additional conductivity of clay minerals. The external factors mainly include mud filtrate invasion, the difference of oilwater bed salinity, limitation of the vertical resolution of well logging instruments in thin interbedded sand and shale, and influence of low-resistivity surrounding rocks. This paper focuses on macro-geological controlling factors of the various internal micro-geological causes of low-resistivity oil layers and the influencing factors of external causes are briefly analyzed.

\subsection{High bound-water saturation}

High bound-water saturation is an important cause for the formation of low-resistivity oil layers and the precondition is that reservoir micro-pores are developed and the motive power of hydrocarbon accumulation can drive oil into flow pores but not enough to displace the highly saline bound water in the micro-pore system (Wu et al, 2006). The pore throat structure of sandstone is influenced by multiple geological factors, in which sedimentation and diagenesis are important.

The Putaohua oil layer in the Puao Oilfield belongs to southern extension zone of the large-scale river-delta deposition system of the Daqing placanticline, and the depositional subfacies change from delta front facies to shoreshallow lake facies and the depositional microfacies change from distal bar and sand sheet to lake mud, beach sand and bar sand (Fig. 2). The low-energy depositional environment leads to fine silt sandstone lithology, high shale content, development of micro-pores, and high capillary resistance. Due to the above factors, reservoir micro-pores are full of bound water and form a conductive network, so oil layer resistivity is low. Based on the core data, the pore structure parameters of low-resistivity oil layers and normal oil layers in the Puao Oilfield were compared and analyzed (Table 1). The results showed that high shale content and uneven distribution of mud in low-resistivity oil layers changed the microstructure of the reservoir to reduce the pore throat diameter and porosity. The relative separation coefficient and structure coefficient of low-resistivity oil layers were less than those of normal oil layers. The bound-water saturation of the reservoir increased owing to the development of micro-pores and poor pore throat structure, so that the low- 
resistivity oil layers with high bound-water saturation and high displacement pressure were formed in the Puao Oilfield.



Fig. 2 Sedimentary facies map of the Putaohua oil layer in the Puao Oilfield
The motive power of hydrocarbon accumulation determines the property and distribution of reservoir fluids when reservoir has the dual pore structure characteristics of micro-pores and flow pores. Water layers are formed when the motive power of hydrocarbon accumulation is less than the intergranular-pore capillary resistance of the reservoir. Low-resistivity oil layers are formed when the motive power of hydrocarbon accumulation is between the intergranularpore capillary resistance and the micro-pore capillary resistance and normal oil layers are formed when the motive power of hydrocarbon accumulation is greater than the micropore capillary resistance (Wu et al, 2006; Palar and Sutiyono, 1997; Li et al, 2006). Therefore, low-resistivity oil layers caused by high bound-water saturation with the bound water in micro-pores and hydrocarbon accumulated in intergranular pores are formed in the reservoir with bimodal or multi-modal pore structure when the source rocks, migration pathway and the motive power of hydrocarbon accumulation are all appropriate.

The diagenesis stage is a long process compared with the deposition stage and a series of complex physical and chemical changes reform the sandstone reservoir $(\mathrm{Fu}, 1998)$. Compaction and cementation reduce and damage reservoir pores, and dissolution and metasomatism increase secondary pores of reservoir. The solution porosity in the Puao Oilfield is mainly from dissolving quartz and feldspar. Feldspar dissolution can generate secondary pores, and a large number of small secondary pores and big pores compose the dual pore structure of reservoir. Therefore, some oil layers become low-resistivity oil layers caused by high bound-water saturation interaction with the motive power of hydrocarbon accumulation.

Table 1 Comparison of pore structure parameters between low-resistivity oil layers and normal oil layers in the Puao Oilfield

\begin{tabular}{ccccccc}
\hline & Parameter & $\begin{array}{c}\text { Relative separation } \\
\text { coefficient }\end{array}$ & $\begin{array}{c}\text { Structure } \\
\text { coefficient }\end{array}$ & $\begin{array}{c}\text { Average value of throat } \\
\text { diameter, mm }\end{array}$ & $\begin{array}{c}\text { Displacement } \\
\text { pressure, MPa }\end{array}$ & $\begin{array}{c}\text { Bound water saturation, } \\
\%\end{array}$ \\
\hline $\begin{array}{c}\text { Normal } \\
\text { oil layers }\end{array}$ & Distribution interval & $0.1-11.3$ & $0.01-5.63$ & $0.04-3.56$ & $0.06-11.6$ & $7.7-39.5$ \\
& Average value & 2.39 & 2.05 & 0.6 & 1.3 & 21.3 \\
$\begin{array}{c}\text { Low-resistivity } \\
\text { oil layers }\end{array}$ & Distribution interval & $0.1-0.24$ & $0.01-0.12$ & $0.02-0.07$ & $10.6-12.06$ & $30.3-61.4$ \\
\hline
\end{tabular}

\subsection{High free-water saturation}

The main geological characteristics of low-resistivity oil layers caused by poor oil-water differentiation and wide oil-water transition zones are the development of primary intergranular flow pores, medium and grit sandstone lithology, high shale content, strong hydrophilic property of the rock, and low structural amplitude of oil layers. Because of the shallow buried depth of the reservoir, the pressure of source rocks and the formation overpressure are very low when oil and gas migrate from source rocks to the trap, and the motive power of hydrocarbon accumulation is mainly buoyancy. The difference between oil and water densities leads to high oil saturation (resistivity increase) at the structural high position and low oil saturation (resistivity decrease) at the structural margin, so low-resistivity oil layers caused by high freewater saturation at the structural margin are formed in the same reservoir system. Based on above analysis, the main geological controlling factors of such low-resistivity oil layers are the motive power of hydrocarbon accumulation and structural amplitude.

The spatial distribution characteristics of developed lowresistivity oil layer wells were analyzed in the Puao Oilfield (Fig. 3). The results showed that the wells in which lowresistivity oil layers were observed were mainly distributed at the structural margin, and only a few were at the structural 
high position. For example, the low-resistivity oil layers of the Ao-4 and Ao-112 wells developed in the uplift zone dipping to the south of the Aonan Oilfield, but the micro-geological cause of such low-resistivity oil layers was not high freewater saturation. Because of low structure amplitude, small oil layer thickness, and the motive power of hydrocarbon accumulation of buoyancy due to the differences of oil-water density in the Puao Oilfield margin, the reservoir does not have a uniform oil-water boundary, and from the structural margin to the structural high position reservoir is mainly an oil-water transition zone with much free water and high water saturation whose average value reaches $48 \%$. Therefore, lowresistivity oil layers caused by high free-water saturation are formed. The water saturation of the low-resistivity oil layer of Mao-741 well reaches $72.4 \%$ and the oil layer resistivity is $2.8 \Omega \cdot \mathrm{m}$, which is typical for a low-resistivity oil layer of this type.

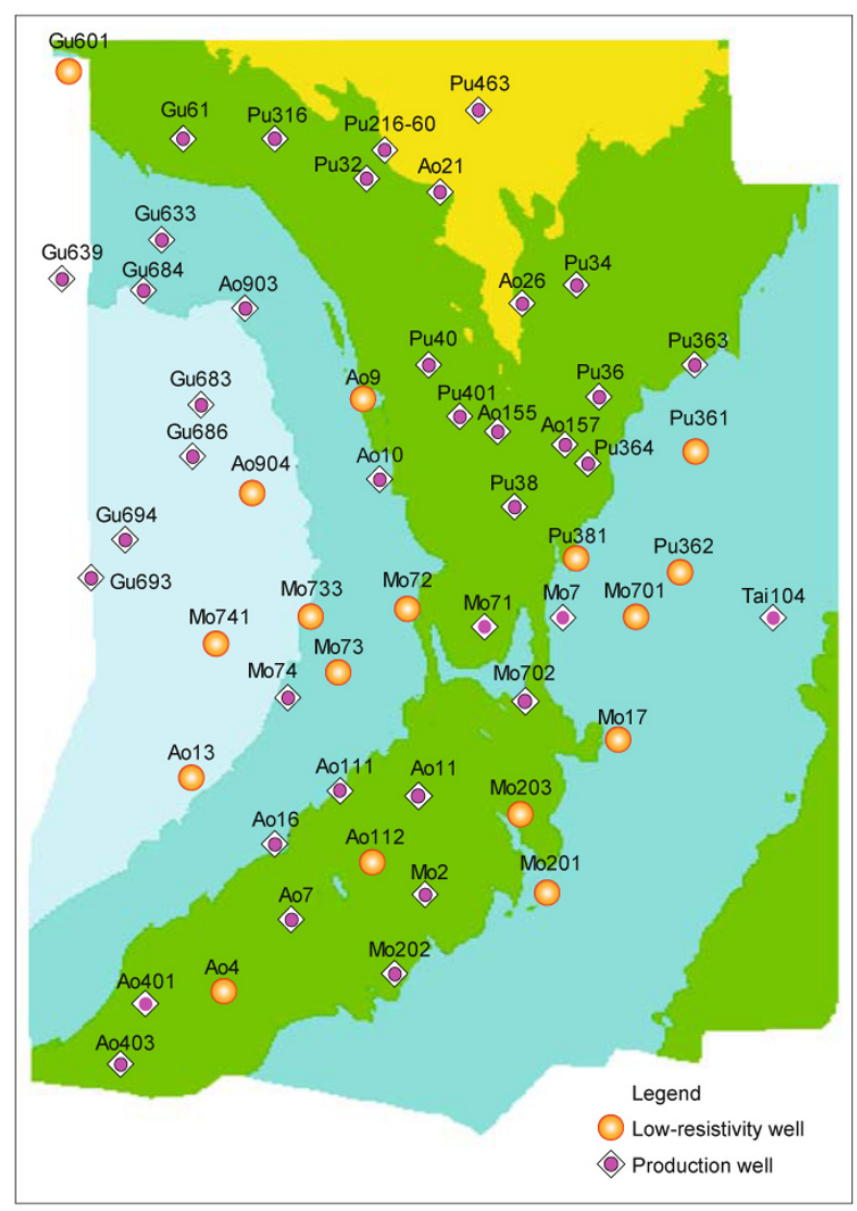

Fig. 3 Well distribution map of low-resistivity oil layers in the Puao Oilfield

\subsection{Formation water with high salinity}

For reservoirs with same lithology and physical properties, with the formation water salinity increasing, the oil layer resistivity decreases, thus the difference between oil layer resistivity and water layer resistivity decreases. When the water layer resistivity is higher than the resistivity of the oil layer, typical low-resistivity oil layers caused by high salinity formation water are formed. Environments such as intermittent salt lake, salt lake, intermittent transgressive saltwater lake, shore-shallow lake subfacies under an evaporative environment, and a sedimentary environment with high salinity water can lead to a reservoir with high formation water salinity. The blocks close to oil sources and faults are the structural zones with accumulation of high salinity formation water and in these places low-resistivity oil layers caused by high salinity formation water are easy to develop ( Wu et al, 2006). Therefore, the main geological controlling factors of such low-resistivity oil layers are sedimentary environments with ancient saline water and faulted structural zones.

The sedimentary environment of the Putaohua oil layers in the Puao Oilfield is from delta front facies to shore-shallow lake sedimentary facies. Stable and relatively shallow water bodies in the depositional process due to weak hydrodynamic force, and salty evaporation environment lead to relatively high formation water salinity, especially the beach and bar microfacies of shore-shallow lake subfacies with formation water salinity of $15,600-18,200 \mathrm{mg} / \mathrm{L}$, which is higher than those of delta front microfacies and the northern Pubei Oilfield by $4,600 \mathrm{mg} / \mathrm{L}$ on average. High salinity formation water can form continuous conductive networks in reservoir pores, so that the oil layer resistivity decreases. The Putaohua oil layers of Mao-17 well, Mao-201 well and Mao-203 well developed in the bar sand microfacies of shore-shallow lake sediments. The average salinity of formation water is 17,565 $\mathrm{mg} / \mathrm{L}$ and the oil layer resistivity is only $4.3 \Omega \cdot \mathrm{m}$, so these oil layers are typical low-resistivity oil layers caused by the sedimentary environment with high formation water salinity. Faults developed in the Puao Oilfield, dividing the structure into twelve separate blocks. Analysis shows the salinity of formation water closer to faults is higher than that of the formation water further from the faults. The main reasons are that the closed traps are destroyed by tectonic movement, the side-bottom water in reservoir or the water from the dissolution of rock minerals in the diagenetic process migrates once again to the reservoir, and even surface water infiltrates into the original reservoir through faults to change the formation water salinity. In the study area, the formation water salinity of wells close to faults is higher than the salinity of original formation water of adjacent wells, so lowresistivity oil layers are formed.

\subsection{Additional conductivity of clay minerals}

Clay minerals are main components of clastic interstitial materials and are distributed in heterocomplex and cementing material (authigenic mineral), mainly in the mud. Generally, the negative charges on the surface of clay particles can cause the adsorption of cations from the formation water in the pore space of rocks to maintain an electrical balance. The cations which are adsorbed are able to exchange their positions on the surface of clay particles and produce additional conductivity which is different from that of free water in reservoir pores. With the number of balance cations (cation exchange capacity) increasing, the additional conductivity of clay minerals becomes stronger and will decrease oil layer 
resistivity to form low-resistivity oil layers (Mu et al, 2004; Wei and Zou, 2005; Gao and Xie, 2006). The cation exchange ability of clay minerals is usually measured by cation exchange capacity (CEC, mmol/100g), and the CEC values of common clay minerals are shown in Table 2.

Table 2 CEC statistics of common clay minerals

\begin{tabular}{ccc}
\hline Types of clay minerals & Density, g/ $\mathrm{cm}^{3}$ & $\begin{array}{c}\text { Average value of CEC, } \\
\mathrm{mmol} / 100 \mathrm{~g}\end{array}$ \\
\hline Montmorillonite & 2.33 & 1 \\
Illite & 2.76 & 0.2 \\
Kaolinite & 2.69 & 0.03 \\
Chlorite & 2.77 & 0 \\
\hline
\end{tabular}

The clay minerals of the Puao Oilfield can be divided into two types according to their causes, one is clay minerals depositing with the terrigenous clast particles, and the other is authigenic clay minerals formed during late diagenesis. The type, composition and distribution pattern of terrigenous clast clay minerals are decided by ancient climate, provenance, and sedimentary environment, and the formation of authigenic clay minerals are mainly controlled by acidity and alkalinity of reservoir fluids. The type and content of clay minerals in the study area were analyzed by X diffraction (Fig. 4 ). The clay minerals are mainly illite, chlorite, and mixedlayer illite-montmorillonite with the average content of $51 \%, 29 \%$, and $14 \%$ respectively, and they are all distributed stably in the study area. Kaolinite and mixed-layer chloritemontmorillonite are distributed in a few wells and there is no montmorillonite detected in samples from oil layers.



Fig. 4 Histogram of type and content of clay minerals in the Puao Oilfield

The sedimentary environment of the Puao Oilfield changes from large-scale river delta front facies to shoreshallow lake facies. Under a warm and humid paleoclimate, some aluminum silicate minerals such as feldspar and mica formed a high proportion of illite after weathering and diagenesis, and some aluminum silicate minerals formed kaolinite after weathering and leaching in an acidic medium. In the study area, because of the alkaline formation water, kaolinite is only distributed in a few wells and the content is low. Pyroxene, hornblende and biotite in terrigenous clasts can form montmorillonite after partial chemical weathering, but this is not found in the study area, because terrigenous clast clay minerals transform into authigenic clay minerals during late diagenesis. The types of clay minerals formed are closely related to the properties of formation water (salinity, ionic composition, acidity and alkalinity) (Fu, 2000; Zhao and Zhu, 2006). The expanding clay mineral, montmorillonite, is formed at $\mathrm{pH}=6-8$. Montmorillonite can transform into non-expanding clay minerals such as illite $(\mathrm{pH}=7-8)$ and chlorite $(\mathrm{pH}=8-9)$ with the increase of formation alkalinity (Guan et al, 2003; Zhao and Zhu, 2006). In the study area, the water type is mainly high in $\mathrm{NaHCO}_{3}$ and the average value of $\mathrm{pH}$ is 8.2 , so the formed montmorillonite from terrigenous clasts completely transforms into illite or mixedlayer illite-montmorillonite in this alkaline environment, and can transform into chlorite or mixed-layer chloritemontmorillonite in a stronger alkaline condition. Based on the above analysis, the types of clay minerals in the Puao Oilfield are mainly illite and mixed-layer illite-montmorillonite and low-resistivity oil layers can be formed because of strong additional conductivity of the two clay minerals. Fig. 5 is a cross plot of oil layer resistivity and the content of illite and mixed-layer illite-montmorillonite in the Puao Oilfield. It is shown that when the content of illite and mixed-layer illite-montmorillonite reaches above $80 \%$, strong additional conductivity can decrease oil layer resistivity to develop lowresistivity oil layers.

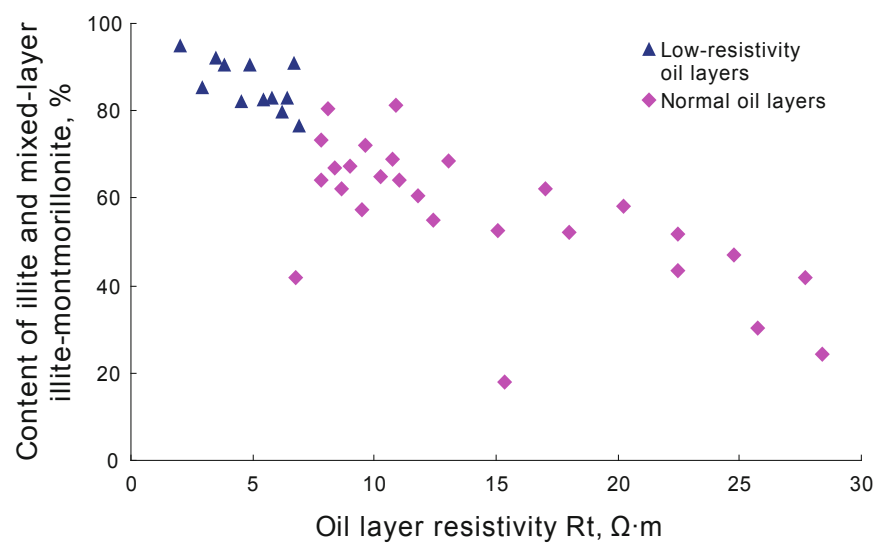

Fig. 5 Cross plot of oil layer resistivity and content of illite and mixed-layer illite-montmorillonite in the Puao Oilfield

The additional conductivity capacity of clay minerals is not only related to their types and contents but also to their distribution patterns, which are mainly bridge, filling, and cushion (Fig. 6), corresponding to "crumb", "thin film", and "patch" mud distribution patterns. The bridge distribution 
pattern leads to a continuous distribution of clay minerals in the reservoir rock to form a connected conductive network, and combined with high cation exchange capacity, lowresistivity oil layers caused by additional conductivity of clay minerals are formed. In the study area, the most common distribution pattern of clay minerals of such low-resistivity oil layer is bridge pattern. Although filling and cushion distribution patterns also have additional conductivity, continuous conductive networks are not formed and the conductivity capacity is too limited to influence oil layer resistivity, so it is difficult to form low-resistivity oil layers from these clay-mineral distribution patterns.
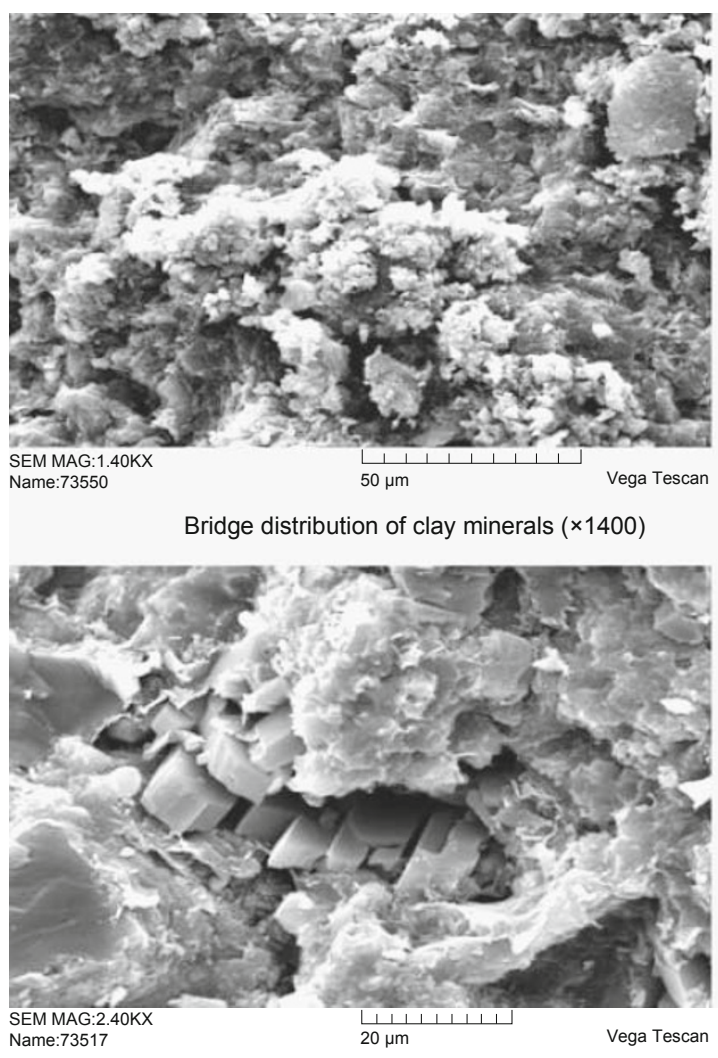

Filling distribution of clay minerals $(\times 2400)$

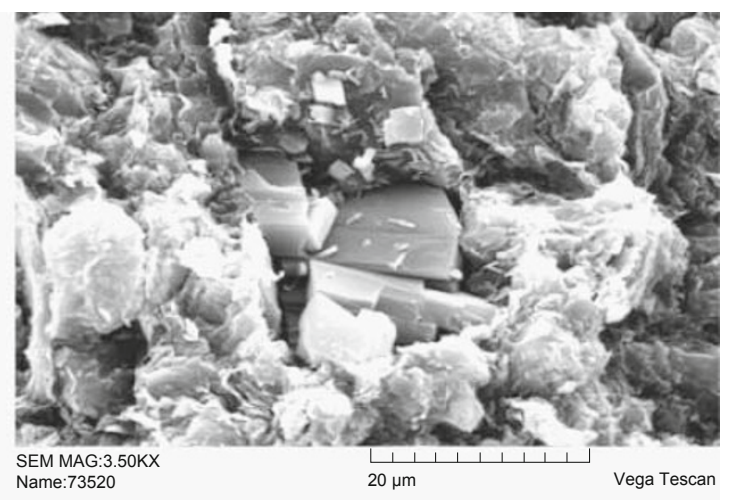

Bridge distribution of clay minerals $(\times 3500)$

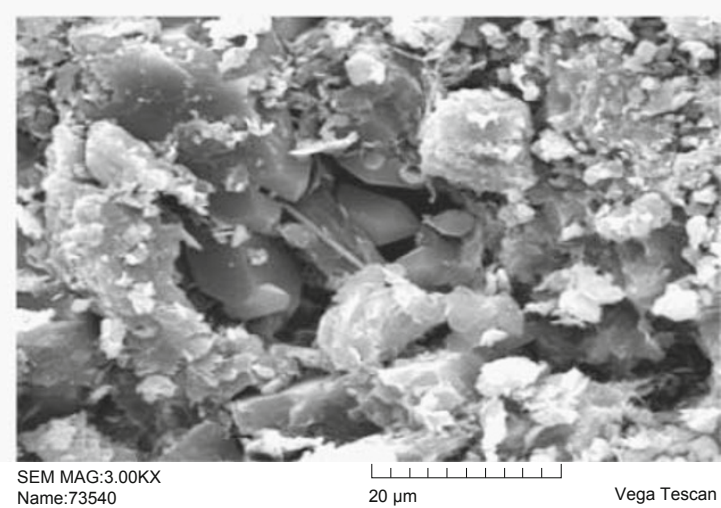

Cushion distribution of clay minerals $(\times 3000)$

Fig. 6 Scanning electron photomicrograph of different distributions of clay minerals

\section{Influencing factor of external causes of low-resistivity oil layers caused by thin interbeds of sand and shale}

The Puao Oilfield was located in the transition zone from delta front facies to shore-shallow lake facies, so hydrodynamic forces were relatively weak and thin interbeds of sand and shale were easily formed because of the reciprocating flow of water. In fact, the resistivity of a single layer of sandstone is not low, but due to the limitation of vertical resolution of well logging instruments, the actual measured value of resistivity decreases because of the influence of low-resistivity surrounding rocks. Thus, the resistivity difference of oilwater layers sharply decreases to form low-resistivity oil layers. Fig. 7 shows the logging interpretation results of Ao112 well in the study area. We can see that No. 59 and No. 63 layers are both low-resistivity oil layers. No. 59 layer is sandstone interbedded in mudstone. The resistivity well logging response of a single layer of sandstone is greatly influenced by the surrounding mudstone, so the response curve shows low-resistivity and peak characteristics. The testing results of No. 59 low-resistivity oil layer are $3.6 \mathrm{t}$ /day of oil production and $0.2 \mathrm{t}$ /day of water, which is classified as a commercial oil layer with low water cut. No. 63 layer is the mudstone interbedded in sandstone. The well logging response of a single layer of sandstone is greatly influenced by interbedded mudstone, so the measurement results are not a reflection of actual reservoir information, and the response curve shows low-resistivity and flat characteristics. The testing results of No. 63 low-resistivity oil layer are $5.31 \mathrm{t} /$ day of oil production and no water, which is classified as a commercial oil layer. In the Puao Oilfield, sandstone interbeds, mudstone interbeds, and thin interbeds of sand and shale developed because of the special sedimentary environment, so lowresistivity oil layers of this type should be paid more attention in reservoir evaluation. 


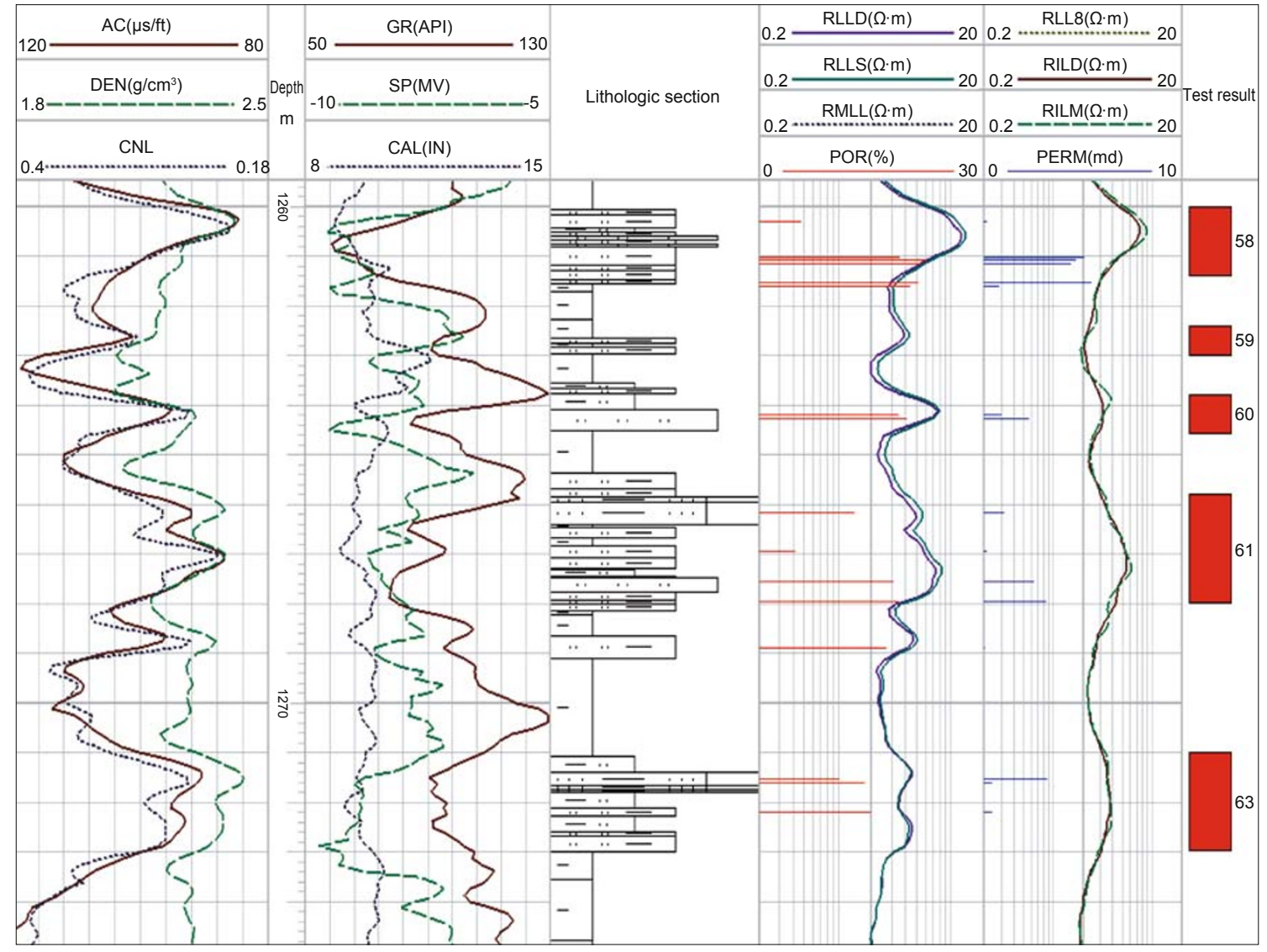

Fig. 7 Well logging interpretation results of Ao-112 well

\section{Conclusions}

1) The formation and distribution of Putaohua lowresistivity oil layers in the Puao Oilfield are controlled by depositional environment, sedimentary facies, diagenesis, motive power of hydrocarbon accumulation, and acidity and alkalinity of reservoir liquid.

2) The low-resistivity oil layers caused by high boundwater saturation are controlled by deposition and diagenesis; those caused by high free-water saturation are controlled by structural amplitude and motive power of hydrocarbon accumulation; those caused by formation water with high salinity are controlled by ancient salty water depositional environment and faulted structure; those caused by the additional conductivity of shale are controlled by paleoclimate and acidity and alkalinity of reservoir liquid.

3) Special depositional environments lead to extensive development of thin interbeds of sand and shale in the study area. Because of the influence of low-resistivity surrounding rocks and limitation of the vertical resolution of well logging instruments, low-resistivity oil layers need to be paid special attention in the evaluation of oil layers.

4) The causes of low-resistivity oil layers are very complex and are influenced by multiple factors. Consideration of the combinations of internal and external factors, and micro-geological causes and macro-geological controlling factors can assist in revealing the nature of low-resistivity oil layers.

\section{Acknowledgements}

This work was supported by the National Natural Science Foundation Project (No.40173023). The authors would like to thank Wang Ming from the Research Institute of Exploration and Development of SINOPEC, and Zhang Shaohua from Changqing Oilfield Company for their helpful discussion and suggestions.

\section{References}

Fu Q. Diagenesis effect on reservoir pores - taking the Rong-37 block of the lower Tertiary, Liaohe Basin as an example. Acta Sedimentologica Sinica. 1998. 16(3): 92-96 (in Chinese)

$\mathrm{Fu} \mathrm{W}$ J. Influence of clay minerals on sandstone reservoir properties. Journal of Palaeogeography. 2000. 2(3): 59-68 (in Chinese)

Gao X and Xie Q B. A survey on mechanism and research advance of low-resistivity reservoir. China Foreign Energy. 2006. 11(6): 28-32 (in Chinese)

Guan J F, Lu Q, Chen L L, et al. Forming and transforming of clay minerals of sandstone and mudstone in Carboniferous-Permian system, south North China Area. Northwestern Geology. 2003. 36(1): 74-77 (in Chinese)

Li Z C, Wu J L, Yu D G, et al. Mechanism of low-resistivity reservoir and identification method of curve shape in Qudi Oilfield. Petroleum Geology and Oilfield Development in Daqing. 2006. 25(6): 102-104 (in Chinese)

Mu L X, Tian Z Y and Zhao L M. Investigation on mechanism of lowresistivity formation of A Oilfield. Acta Petrolei Sinica. 2004. 25(2): 69-73 (in Chinese) 
Ouyang J. A study on saturation-resistivity distribution pattern of reservoirs-An in-depth analysis for the basic origin of lowresistivity reservoirs. Petroleum Exploration and Development. 2002. 29(3): 44-47 (in Chinese)

Ouyang J, Wang G W, Wu J Y, et al. Logging Geology Analysis and Petroleum Quantitative Evaluation. Beijing: Petroleum Industry Press. 2005. 130-140 (in Chinese)

Palar S and Sutiyono S. Approaches in evaluating low-resistivity formations. Asia Pacific Oil and Gas Conference and Exhibition, Kuala Lumpur, 14-16 April 1997. 173-182 (SPE 38036)

Sun J M, Chen G H, Yang Y Z, et al. Low contrast resistivity reservoir evaluation method. Acta Petrolei Sinica. 1998. 19(3): 83-88 (in Chinese)

Wei Z L and Zou C C. Geophysical Well Logging. Beijing: Geological Publishing House. 2005. 68-73 (in Chinese)
Worthington P F. Recognition and development of low-resistivity pay. Asia Pacific Oil and Gas Conference and Exhibition, Kuala Lumpur, 14-16 April 1997. 157-171 (SPE 28035)

Wu J L, Sun J M, Zhu J J, et al. Study on macro-geologic control genesis of micro-geological causes in low-resistivity oil layer of Jiyang Depression. Journal of China University of Petroleum (Edition of Natural Science). 2006. 30(3): 23-35 (in Chinese)

Zeng W C. Type, genesis and evaluation method of low-resistivity oil and gas layers. Well Logging Technology. 1991. 15(1): 6-12 (in Chinese)

Zhang C, Mao Z Q, Zhang C, et al. A survey on genetic mechanism and identification methods of low-resistivity layer. Chinese Journal of Engineering Geophysics. 2008. 5(1): 48-53 (in Chinese)

Zhao C L and Zhu X M. Sedimentary Petrology. Beijing: Petroleum Industry Press. 2006. 117-122 (in Chinese)

(Edited by Hao Jie) 